\title{
(a)
}

\section{Gobernar la casa, la familia y a sí misma: imperativos de la educación infantil femenina en Colombia en la primera mitad del siglo $\mathbf{X X}^{*}$}

Governing Home, Family and Themselves: Imperatives of Female Early Childhood Education in Colombia (First Half of the 20th Century)

Governar o lar, a família e a si mesma: imperativos da educação infantil feminina na Colômbia (primeira metade do século XX)

Ana Cristina León-Palencia** iD orcid.org/0000-0001-7489-0681

Para citar este artículo: León-Palencia, A. (2021). Gobernar la casa, la familia y a sí misma: imperativos de la educación infantil femenina en Colombia en la primera mitad del siglo xx. Revista Colombiana de Educación, 1(82), 411-428. https://doi.org/ 10.17227/rce.num82-11381

$\begin{array}{rr}\text { (c) } \text { (i) }_{\text {BY }} \text { Na } & \text { Recibido: } 28 / 02 / 2020 \\ \text { Evaluado: } 06 / 08 / 2020 \\ 25 / 08 / 2020 \\ 11 / 08 / 2020\end{array}$

* Los resultados presentados en este artículo de investigación se derivan de la investigación titulada Cons titución del sujeto infantil femenino en Colombia: Finales del siglo xIx, comienzos del xx (2012), elaborado en el marco de la Maestría en Educación de la Universidad Pedagógica Nacional.

** Magíster en Educación. Profesora de la Universidad Pedagógica Nacional, Bogotá, Colombia. Miembro de Grupo de investigación de Historia de la práctica pedagógica en Colombia. Correo: acleon(a)pedagogica.edu.co 


\section{Resumen}

Este artículo de investigación presenta algunos resultados de un estudio sobre las prácticas de educación de la niña en Colombia a finales del siglo xix e inicios del siglo xx. Tales prácticas emergieron en el marco de tres desplazamientos: en primer lugar, una modificación en la comprensión de lo femenino, sintetizada en el paso del bello sexo a la mujer moderna; en segundo lugar, los ajustes en la educación de las niñas que pasaron del espacio familiar a la escuela; en tercer y último lugar, se instaló una figura de la mujer en el ámbito social más ligada a su papel de madre que al de esposa. Estos desplazamientos sirvieron como condición de posibilidad para un tipo de prácticas educativas cuyo objetivo se centró en el imperativo: gobernar a otros y a sí misma. Esto implicó que, aunque las prácticas de educación femenina mantuvieron su confinamiento en el hogar, la mujer se tornara en pieza fundamental de las estrategias de gobierno de la población en la primera mitad del siglo xx. A partir de la lectura temática de manuales de pedagogía, urbanidad, puericultura, higiénicos, de revistas médicas y pedagógicas de amplia circulación, de normatividad educativa, entre otras fuentes documentales analizadas a través de las herramientas de carácter arqueológico de cuño foucaultiano, en el texto se desarrollan tres asuntos: uno de orden conceptual, otro de carácter político y uno más de tipo práctico.

\section{Palabras clave}

Educación femenina; historia de la educación; pedagogía; gobierno; educación estética

\section{Keywords}

Female education; history

of education; pedagogy; government; aesthetic education

\begin{abstract}
This research article presents some results of a study on the practices of girl education in Colombia, at the end of the 19th century and the beginning of the 20th century. Three displacements framed the emergence of these practices: first, a modification in the understanding of the feminine, synthesized in the passage from beautiful sex to modern women. Second, the adjustments in the education of girls who moved from family space to school. Third and last, a figure of the woman appeared in the social sphere more linked to her role as mother than that of wife. These displacements served as a condition of possibility for a type of educational practices, whose objective was focused on the imperative: to govern other women and themselves. This implied that, although the practices of feminine education maintained their confinement in the home, the woman became a fundamental part of the strategies of government in the first half of the 20th century. From the thematic reading of pedagogy, urbanity, childcare, hygienic manuals, medical and pedagogical journals of wide circulation, educational regulations, among other documentary sources analyzed through the tools of Foucauldian wedge, in the text three issues are developed: one of a conceptual nature, another of a political type and one more of a practical kind
\end{abstract}

\section{Resumo}

Este artigo de pesquisa apresenta alguns dos resultados de um estudo sobre as práticas educacionais de meninas na Colômbia no final do século xIx e no início do século xx. Tais práticas emergiram no quadro de três deslocamentos: primeiro, uma modificação na compreensão do feminino, sintetizada na passagem do belo sexo para a ideia da mulher moderna; segundo, os ajustes na educação das meninas que mudaram do espaço familiar para a escola; finalmente, a figura da mulher, instalada na esfera social, mais ligada ao seu papel de mãe do que a da esposa. Esses deslocamentos serviram como condição de possibilidade para um tipo de práticas educacionais cujo objetivo centrou-se em o imperativo: governar aos outros e a si mesmas. Isso implicava que, embora as práticas de educação feminina mantivessem seu confinamento no lar, a mulher tornou-se parte fundamental das estratégias de governo da população na primeira metade do século xx. Desde a leitura temática de manuais de pedagogia, urbanidade, puericultura e higiene, periódicos médicos e pedagógicos de ampla circulação, regulamentos educacionais, entre outras fontes documentais analisadas através das ferramentas da cunha foucaultiana, desenvolveram-se três questões: uma de natureza conceitual, outra de carácter político e, finalmente, outra de tipo prático.

\section{Palavras-chave}

Educação feminina; história da educação; pedagogia; governamento; educação estética 


\title{
Introducción
}

\author{
Una muger amable, templada, modesta, que inspecciona, y \\ dirige todas las operaciones de su familia, que educa a sus hijos, y \\ hace feliz al compañero de su suerte, si ademas de estas prendas \\ esenciales, sabe tomar parte en una conversacion interesante, \\ dibujar con gusto, y correccion, cantar con alma, y método, \\ y descifrar en el piano una sonata, reúne todo cuanto puede atraerle \\ al alma, y recrea, y distrae la imaginacion. Con esta variedad \\ de recursos puede aligerar el peso de sus males, suavizar el rigor de \\ las obligaciones, dar nuevos atractivos a la vida domestica, y hacer \\ durable e irresistible su imperio.
}

En tiempos de radicalismos, estudiar lo femenino convoca a polarizaciones y politizaciones a propósito de la idea de género, a la defensa de los derechos de la mujer y a reconocer aquellas relaciones cada vez más tensas con el universo masculino. El análisis que se presenta a continuación, antes que un estudio de género, constituye un esfuerzo por entender desde una óptica educativa la manera como lo femenino tomó forma en las prácticas educativas identificables entre finales del siglo xIx e inicios del siglo xx en Colombia' ${ }^{1}$. Desde esta perspectiva, es precisa una declaración: este estudio puede comprenderse como radicalmente pedagógico.

Lo anterior no evade el reconocimiento a los estudios de género. Por el contrario, recuerda la necesidad de precisar aquello que constituye un estudio de este orden. Para ello, se abordan los planteamientos de la historiadora estadounidense Joan Scott (1990), quien realiza un balance general a propósito de este asunto y designa a qué aludirían dichos estudios describiéndolos en tres líneas. En la primera, se instalan aquellos trabajos que denotan una problematización de lo femenino y que indican, por una parte, el rechazo al determinismo biológico implícito en el uso de términos como sexo o diferencia sexual; por otra parte, se refieren a aquellas investigaciones que aluden a las mujeres como pretexto para desmarcarse de la política del feminismo e ingresar con cierta legitimidad a las discusiones

1 Es conveniente indicar aquí dos cuestiones de método: la primera, que es posible localizar este análisis en Colombia por cuanto se analizaron numerosas fuentes documentales de distinta naturaleza, producidas para el periodo de estudio en el país, entre ellas, artículos en publicaciones seriadas de circulación nacional y especializadas en educación, manuales de urbanidad, manuales de puericultura, manuales de economía doméstica, documentos dirigidos a la educación femenina, entre otros. Tal revisión, de la que aquí apenas se retoman algunas referencias, permitió describir discursivamente una manera de comprender la infancia femenina. La segunda, que fue posible reconocer la circulación de algunos de estos textos en prácticas concretas de educación femenina, dada su referencia en los planes de estudio de diversas instituciones escolares dedicadas a esta educación; no obstante, un análisis sobre el "impacto" de estos discursos correspondería a un estudio de naturaleza metodológica distinta a la que aquí se pretendió. 
académicas; o, finalmente, como analogía a los conceptos de clase o raza, considerándose como una respuesta a los análisis desde los oprimidos o las desigualdades.

En la segunda línea se nombran los desarrollos de las historiadoras feministas que han trabajado en tres ejes: el feminismo y los orígenes del patriarcado, la tradición marxista — en la cual el género carecería de un estatus analítico propio- y los trabajos basados en las escuelas de psicoanálisis que explican la producción y reproducción de la identidad de género del sujeto.

En la tercera y última línea, Scott (1990) describe su postura para entender el género, al situarla como una categoría analítica que permite hablar de los sistemas de relaciones sociales o sexuales como campos de fuerza social y que comprende cuatro elementos ineluctables: los símbolos culturalmente reconocibles; los conceptos normativos que manifiestan los significados interpretados de los símbolos, con la intención de descubrir la permanencia intemporal de ciertos discursos naturalizados en la representación binaria de género; la inserción de nociones políticas, referidas en las instituciones y organizaciones sociales; y el análisis de la identidad subjetiva y las formas como esta se construye. Así las cosas, el presente trabajo no usa como categoría de estudio la noción de género, por lo tanto, no puede inscribirse en dicha perspectiva.

En lugar de ello, este se aproxima a una perspectiva distinta, desde la cual es preciso reconocer la discusión relativa a las formas en que el sexo es regulado, normatizado y materializado. En este caso se retoma el análisis de la filósofa estadounidense Judith Butler, para quien la categoría sexo es normativa, y se remite a Foucault, quien plantea que este constituye un ideal regulatorio. Es decir, el sexo

no solo funcionaría como norma, además, es parte de una práctica reguladora que produce los cuerpos que gobierna, es decir, cuya forma reguladora se manifiesta como una forma de poder productivo, el poder de producir - demarcar, circunscribir, diferenciar- los cuerpos que controla. De modo tal, que el "sexo" es un ideal regulatorio cuya materialización se impone y se logra (o no) mediante ciertas prácticas sumamente reguladas. En otras palabras, el "sexo" es una construcción ideal que se materializa obligatoriamente a través del tiempo. (2002, p. 18)

Se plantea, así, la materialización de los cuerpos como efecto de un poder productor que regula a través de ciertas normas y prácticas históricas. En esta lógica, la escuela sería un lugar de reiteración y circunscripción a ciertas normas y prácticas reguladoras que cuestionarían cuáles son las normas que regulan la materialización del sexo infantil femenino y, de estas, cuáles circulan en el terreno escolar. A su vez, la existencia y legitimación de dichas normas sería posible en la medida en que existan actos de reiteración 
o actos performativos. La performatividad no debe entenderse como un acto singular y deliberado, sino como la práctica reiterativa y referencial mediante la cual el discurso produce los efectos que nombra. En tal sentido, las normas reguladoras del sexo operan de manera performativa para constituir la materialidad de los cuerpos y, específicamente, para materializar el sexo del cuerpo que caracteriza la diferencia sexual y busca consolidar el imperativo heterosexual. Las prácticas que posibilitan tal configuración se encontrarían en juego, la performatividad que no sería siempre la misma, la cita a la norma, su puesta en escena, su teatralidad, permiten la regulación del sujeto, crean sus fronteras, permiten su naturalización.

Para pensar estos elementos, se recurre a los análisis históricos que visibilizan las prácticas que posibilitaron la configuración de la niña en el espacio social. Desde la perspectiva arqueológica y genealógica acuñada por el pensador francés Michel Foucault, se analizaron diversos documentos producidos durante finales del siglo XIX y comienzos del xx; entre estos se identifican manuales de pedagogía, urbanidad, puericultura, higiénicos, revistas médicas, pedagógicas y otras de amplia circulación, normatividad educativa, entre otras fuentes. Con base en esa revisión, el presente trabajo se centra en la descripción de algunos elementos relacionados con una manera particular de gobierno de la infancia femenina, valga decir, una forma de orientar la conducta de la niña a partir de sus prácticas de conducción del hogar, la familia y de sí misma. Para ello se recurre a tres asuntos: uno de carácter conceptual, otro político y otro práctico.

\section{Del bello sexo a la mujer moderna}

El primer asunto, de carácter conceptual, describe el modo como se representó a la mujer durante finales del siglo XIX y comienzos del Xx, que, siguiendo a Sánchez (1999), se llevó a cabo en dos momentos que explican los procesos de subjetivación femenina. El primero, situado en lo que se nombró como el bello sexo; y el segundo, en su paso a la idea de la mujer moderna. Estos se encontrarían en su concepción sobre la naturaleza del alma femenina y se distanciarían frente a su comprensión del cuerpo femenino. En el caso de la primera, a partir de una enunciación del cuerpo como enfermo, mientras la segunda remite a la consideración de un cuerpo fuerte y vigoroso.

En el escenario de la mujer nombrada desde el bello sexo se la reconoce como débil y pasiva (Bermúdez, 1993), devota, pero no en exceso, a la vez esposa y madre. Por ello era educada en ciertas artes, como lo señala Ackermann (1824) en el epígrafe: el canto, el dibujo, participar en conversaciones, entre otras prácticas dirigidas a exhibirse en encuentros sociales y evidenciar que era una esposa digna de mostrar. No es necesario que estudie ciencias, pero es imperdonable su ignorancia en las labores "mugeriles del

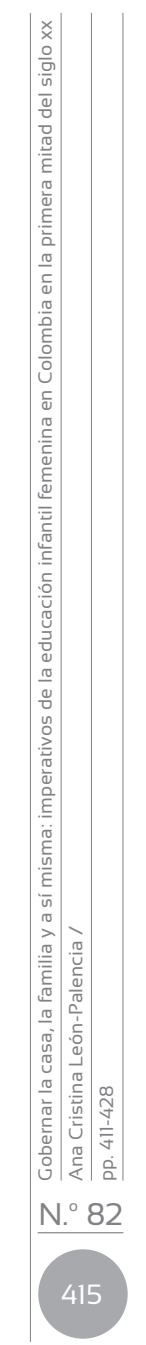


gobierno de la casa, i de los quehaceres i minuciosa economía doméstica" (Acevedo de Gómez, 1848, p. 65). Si bien son labores de la mujer — según se enuncia - las prácticas restringidas al hogar, su papel como esposa implica ciertos saberes, por ello es ingente su educación. Será quizá este el lugar que ocupa con más claridad durante el siglo XVIII y las primeras décadas del XIX.

El bello sexo ubica la belleza femenina no solo en lo físico, sino fundamentalmente en lo moral, reconociendo allí la importancia de una mujer religiosa que actúe según las normas sociales. Por esto, se reprochan comportamientos referidos al mundo público, como las reuniones sociales, la preocupación exagerada por lucir a la moda -que aparece reiterativamente en las fuentes consultadas-, una inquietud por la circulación de literatura que exacerba la imaginación, entre otros oficios que se consideran ociosos en relación con las labores mujeriles "domésticas". Ello es producto de las tendencias naturales de la mujer que, situadas en el terreno sensible, indican, entre otras cosas, una predisposición a sucumbir a sus pasiones y a la imaginación. De allí que sea necesaria la educación moral. De este modo:

Hay un camino sensible y práctico para afirmar el conocimiento de esta distinción entre el cuerpo y el alma, y es acostumbrar a los niños a despreciar el uno y a estimar a la otra en todos los detalles de su vida. Elogiad la instrucción, que nutre y hace crecer al alma; estimad las altas verdades que la impulsan a ser juiciosa y virtuosa; despreciad la buena vida, los adornos y todo lo que vuelve blando el cuerpo; haced percibir que el honor, la buena conciencia y la religión están por encima de los placeres groseros. (Fenelón, 1934, p. 65)

A su vez, dichas fuerzas ociosas se expresan en prácticas más dirigidas a lo decorativo que a lo útil. Esto resultaría lamentable, pues se alude a una suerte de pérdida de tiempo frente a lo que se considera ha de tener una ocupación mayor para la mujer, es decir, los quehaceres del hogar:

La moda ha introducido otra manera de perder el tiempo trabajando, cosa que parece una paradoja, i que sin embargo, es una verdad evidente. Las fajitas de abalorio, los bordados de lomillo en angeo, las sortijas de pelo, i otras frioleras de este jaez, han tenido sus épocas, i las mugeres (sobre todo, las que llaman de tono) no se han avergonzado de pasar meses enteros trabajando ociosamente en estas inutilidades, con perjuicio de la economía doméstica, del cuidado de la familia, i la moda, como se sabe, es un tirano mui exijente. [...] me parece incomprensible es que una madre de familia abandone sus quehaceres, durante una larga temporada, para dedicarse exclusivamente a semejantes futilezas. El abuso en todas las cosas es pernicioso, i este es el que creo reprobable. (Acevedo de Gómez, 1848, pp. 11-12)²

2 En esta, como en otras referencias utilizadas, se respetó la ortografía usada en el periodo de publicación. 
La preocupación por la belleza corporal es un asunto que requiere limitarse, dado que si no se regula puede exacerbar la vanidad femenina, que deriva del deseo de agradar, conduciendo a engalanar los cuerpos, a conversaciones insinuantes y al apasionamiento por los adornos. A todos estos asuntos debe temerse.

Del mismo modo, la lectura, aunque se encuentre en la órbita de lo que es más grato y provechoso, contiene múltiples inconvenientes que han de evitarse, ya que su práctica direccionada equívocamente puede favorecer el incumplimiento de sus deberes mujeriles, al mismo tiempo que desborda la imaginación y procura desvíos guiados por la curiosidad.

\begin{abstract}
las niñas mal instruidas y desaplicadas tienen una imaginación siempre errante. A falta de alimento sólido, su curiosidad se dirige ardientemente hacia los objetos vanos y peligrosos. Las que tienen ingenio se vuelven a menudo pedantes y leen todos los libros que puedan alimentar su vanidad; se apasionan con las novelas, con las comedias, con relatos de aventuras quiméricas en las que se mezcla el amor profano. Su espíritu se vuelve visionario al acostumbrarse al lenguaje magnificente de los héroes de novela; $y$, además, se desorientan con ello para vivir en el mundo, puesto que todos estos bellos sentimientos en el aire, todas estas pasiones generosas, todas estas aventuras que el autor de la novela ha inventado para el placer, no tienen ninguna relación con los verdaderos motivos que dirigen la conducta en el mundo y que son decisivos en todos los asuntos, ni con los desengaños que se encuentran en todas las obras que se emprenden. (Fenelón, 1934, p. 13)
\end{abstract}

Una vez apartadas de libros profanos (novelas y comedias), se les invita a conocer de historias griegas, romanas o la historia de su país, con el objetivo de encauzar el alma hacia sentimientos elevados y evitando así la vanidad. Se sugiere la lectura de obras de elocuencia y poesía para fortalecer el don de la palabra, siempre que se haga con exacta sobriedad. No se trata de situar la lectura en la lista de prácticas proscritas para la niña, por el contrario, se busca que, aun cuando se señalen los peligros, pueda aprovecharse esta como un medio eficaz, que dirija a las obligaciones y al amor por la virtud, en libros que ofrezcan las ventajas de las buenas acciones y las inconveniencias de las malas, sirviéndose de estos, en su máximo aprovechamiento (Ackerman, 1824).

Según se expresa, las mujeres se dejan moldear mucho más que los hombres por lo que leen, a causa de la vivacidad de su imaginación y de su inteligencia. Maravillaba ver cómo ciertas lecturas desarrollaban en ellas las virtudes, a la vez que provocaba temor evidenciar los lamentables efectos de las malas lecturas (Dupanloup, 1995/1888). En este sentido, Dupanloup $(1995 ; 1988)$ señala que la mujer debe estudiar aquello que le es útil como madre y como esposa, permitiendo diferenciar a las mujeres juiciosas de las casquivanas, estas últimas incompetentes para educar a sus hijos: 
lo que pido ante todo no son mujeres sabias, sino —algo que es necesario tanto para sus maridos como para sus hijos y su hogar- mujeres sensatas, juiciosas, aplicadas, instruidas de cuanto les es necesario y útil saber en su calidad de madres, amas de casa y mujeres de mundo; pido que sean atentas, reflexivas y laboriosas. $Y$ añado que lo que hay que temer como a los mayores males son esas mujeres frívolas, casquivanas, perezosas, ociosas, ignorantes, disipadas, amantes del placer y de la diversión y por consiguiente enemigas de todo trabajo y de casi todo deber, incapaces de cualquier atención sostenida y, por ende, incompetentes para tomar realmente parte en la educación de sus hijos. (Dupanloup, 1995/1888, p. 34)

Se entiende así que no se trata de educar a una mujer pedante, sino que se quede en casa, que siendo instruida sepa instruir a sus hijos, en vez de hablar de vestidos y diversiones. Que sea capaz de escuchar al marido y conversar con él. En suma, una mujer que cumple la finalidad de la unión conyugal: "la que es para su marido una verdadera compañera, es decir, como dice la Escritura, un auxiliar y un apoyo en la vida. Socia, adjutorium" (p. 31).

También se señala a la ociosidad intelectual de las mujeres como causa de cierta molicie del alma y el carácter, causante de los peligros del hogar, pues son tristes aquellos hogares donde las mujeres se han dedicado a frivolidades y pérdida de tiempo. Por ello, deben cultivarse a sí mismas mediante hábitos de trabajo intelectual comedido y ordenado, siendo estos de gran ayuda para cumplir con los deberes de mujer cristiana. En particular, estas prácticas se dirigían a mujeres de una clase social alta, cuyas preocupaciones excedían la sobrevivencia y tenían mayor probabilidad de participar en una vida social pública, de alfabetización y de entrega a ciertos placeres.

Para ampliar la comprensión de la noción de bello sexo, es necesario explorar la idea de naturaleza femenina, que implica, por un lado, una suerte de "esencialismo" — valga decir, que es algo con lo que se nace-y, por el otro, que tal naturaleza debe ser dirigida convenientemente, sobrellevándola y aceptándola. A la mujer se le otorga una serie de características, como sensibilidad, delicadeza o curiosidad, que conducirán a una lectura moral sobre ella, así como a unas prácticas específicas sobre sí misma y otros.

Es verdad: la mujer tiene en la sociedad una función privativa; una función que sola ella puede desempeñar: la de criar física y moralmente á los pequeñuelos, que han de ser renovación y adelantamiento de la familia y de la patria (que es la familia grande). Toda condición social que contraríe ó menoscabe esta función privativa de las mujeres, no podrá dejar de ser funesta para la familia y la sociedad civil, cuyo mayor bien está en renovarse con una juventud física y moralmente sana. 
Luego de la noción de bello sexo emerge la de mujer moderna, que vincula lo femenino con asuntos distintos. Si bien ella continúa en el mundo del hogar siendo esposa y madre, no lo hace de la misma forma. No se mantiene el imaginario de cierto temor a lo femenino que reinaba en el bello sexo y que implicaba alejarla de alguna literatura, del mundo social o de prácticas inútiles. Por el contrario, la mujer moderna será exaltada por mantenerse en el hogar, como "reina del hogar", privilegio que hasta hace algunas décadas solía reconocerse.

Si bien la mujer siguió restringiéndose a este escenario, lo hizo de manera distinta al entrar en declive su papel "decorativo" como esposa y madre, para convertirse en piedra angular en la estrategia de gobierno de la población durante finales del siglo xix y comienzos del $x x$ —por lo menos para el caso colombiano- - El papel de la mujer fue favorecido, entre otras cosas, porque de ella dependía la felicidad de la familia, dado su carácter, afabilidad de maneras y lo apacible de su trato hacia los demás. Entonces:

Una mujer que generalmente es dulce, afable, afectuosa é indulgente, puede decirse que está como rodeada de una atmósfera cuya influencia en extremo benéfica y agradable hace que todo marche sin tropiezo, facilitando á cada cual el modo de cumplir debidamente con sus obligaciones. Por el contrario, más de una buena ama de casa, pero cuyo aspecto casi siempre revela desagrado y ansiedad, y que con frecuencia usa de expresiones ásperas y reprensiones severas, lo único que obtiene es destruir todo el bienestar y comodidad que de otro modo resultaría de su sistema, orden, aseo y economía. (Atkinson et ál., 1888, p. 171)

Además, se permitió que el cuerpo femenino, otrora restringido a las miradas, escondido e histérico ${ }^{3}$, fuese ahora expuesto en la publicidad de cigarrillos, licores y automóviles, el impulso de productos para mejorar la salud, el uso de aparatos domésticos, la promoción de artes gráficas o artículos exclusivamente femeninos, como modas y cosméticos. El tránsito de la comprensión de la femineidad como bello sexo a entenderla como mujer moderna marcó diferencias entre las formas de ser mujer del siglo xIx o mujer del siglo xx en el país, además, posibilitó que lo que se ha denominado dispositivo de maternalización-infantilización se instalara en el concierto social. En términos generales, tal dispositivo describe una forma particular de ser mujer-madre, que definió el modo

3 Sánchez (1999) lo concibe como un cuerpo femenino saturado de sensibilidad, es decir, un cuerpo atiborrado de sexualidad al que se le atribuyen patologías de orden médico y que establece una comunicación orgánica entre el cuerpo social, el espacio familiar y la vida de los niños. Por lo tanto, a este se le otorga el compromiso de regenerar la civilización, deber asignado a las mujeres de diferentes clases, etnias o razas, por medio de ocupaciones que trascendieran lo familiar (en sus roles de esposa y madre), asumiendo otros roles sociales, como los de enfermera o maestra. 
de practicar la vida femenina a la vez que la infantil, dado que representó la conformación de una infancia ${ }^{4}$ dependiente del cuidado materno. De este modo, madre e infancia se nutrieron mutuamente mediante dicho dispositivo que operó a través de al menos tres mecanismos: la responsabilidad social asignada a la madre, en cuyas manos se delegó el futuro de la nación; la culpabilización a las madres dadas las denuncias de alta mortalidad infantil promulgadas desde el discurso médico de la primera mitad del siglo $x x$, y la alianza entre médico y madre, que favoreció la legitimación de ambas figuras ${ }^{5}$.

\section{El gobierno de los otros: educar la ciencia del hogar}

En segundo lugar, como asunto político, la educación infantil femenina se plantea como pieza fundamental para el gobierno de la población, por cuanto conjuga la conducción o el gobierno de los otros con el de sí misma. En relación con el gobierno de los otros, hay una preocupación especial por educar a las niñas en la ciencia del hogar, lo que supone "instruirlas en los quehaceres domésticos, en el gobierno y manejo de la casa, en el cuidado de los niños y en cuanto á la mujer atañe, como hija, como esposa y como madre" (Arkinson et ál., 1888, p. 3).

Para ello, debe acostumbrarse a las niñas desde temprano a ese gobierno doméstico, dado que de ella dependerán las condiciones físicas, morales e intelectuales de las generaciones futuras, pues será ella quien ha de conducir la conducta de sus hijos. Debido a que ella no va a gobernar el Estado, no requiere conocimientos procedentes de la política, el arte militar, la jurisprudencia o la filosofía, porque su habilidad está dispuesta para emplearla en su hogar. Sin embargo, sí requiere saber hacer las cuentas usando la aritmética, mantener en estado higiénico su casa, emplear sus conocimientos de costura en el vestuario de su esposo, hijos y el suyo propio, además de disponer su sentido estético para embellecer su vivienda. Por supuesto, de su espíritu de orden dará cuenta el orden de su morada, así como la riqueza y salud de su familia lo dará de su buena administración del hogar. Así, la mujer alimentará adecuadamente a sus hijos y esposo, no solo física sino además moralmente, usando para ello sus conocimientos en administración del hogar y en aritmética, resaltando, por supuesto, su espíritu de ahorro, pues

Las mujeres tienen muchísimo más desarrollada que el hombre la capacidad administrativa. El hombre produce y gasta. La mujer es un animal conservador. [...] De todos modos, no hay duda de que en un pueblo

4 Otra óptica analítica a propósito de la infancia se encuentra en Marín-Díaz y León-Palencia (2018).

5 Estos elementos fueron desarrollados de manera detallada en León (2012) y León (2016). 
gobernado por mujeres se comerá infinitamente mejor que en los pueblos gobernados por hombres. Nadie como las mujeres podrá confeccionar los presupuestos para hacer las compras. Los ciudadanos aportaríamos lo que pudiéramos al fondo común y tendríamos a todo momento, buenas o malas nuestras sopitas calientes. (Cambell, 1926, p. 1228)

A propósito del gobierno de sí misma, se indica que este es una condición para administrar correctamente la casa. En otras palabras, se trata de autorregularse, lo cual supone una suerte de obediencia a la razón —no representada en sumisión-, que consiste en

[El] consentimiento con lo que dicta una autoridad bien gobernada. La razón es la primera que ha de obedecer, y para esto es preciso que todos los preceptos se funden en la razón. Siendo la niña objeto de una educación dirigida por las ideas de virtud y amor a sus obligaciones, no será difícil gobernarse en lo cotidiano, ni en las dificultades que se le presenten, ejerciendo sobre sí un autodominio. (Castellanos, 1933, p. 106)

Esta sería evidencia de los actos de alguien libre. Como se muestra, se encuentran en juego tanto la obediencia como la libertad; la tensión entre estos dos aspectos da cuenta del gobierno de sí misma ${ }^{6}$. Sin embargo, para que la niña aprenda a hacer uso de ambas, y dada la debilidad de su espíritu, en el proceso educativo es necesario usar ciertas prácticas que le permitan dicha autorregulación:

Es preciso reprimir en las niñas las amistades demasiado tiernas, las pequeñas envidias, los cumplimientos exagerados, las adulaciones, las vehemencias; todo esto las perjudica y las acostumbra a encontrar todo lo que es grave y serio muy seco y muy austero. Es preciso también proceder de manera que estudien la manera de hablar corto y preciso. El buen ingenio consiste en suprimir todo discurso inútil y en decir mucho en pocas palabras; al contrario de lo que hacen la mayor parte de las mujeres, que dicen poco en muchas palabras. Ellas confunden la facilidad de palabra y la viveza de imaginación con el ingenio; no eligen entre sus pensamientos; no ponen orden ni relacionan las cosas que explican; son apasionadas en casi todo lo que dicen, y la pasión les hace hablar mucho; sin embargo, no puede esperarse nada bueno de la mujer si no se la obliga en seguida a que reflexione, a examinar sus pensamientos, a explicarlos de un modo breve, y a saber callarse enseguida. (Fenelón, 1934, p. 91)

6 En este sentido, es importante recordar la paradoja que señalan Marín y Noguera (2013) como elemento constitutivo de la pedagogía moderna, como aparece en la Pedagogía de Kant: la libertad constituye un fin, un objetivo, para el cual se requiere ineludiblemente de la coacción propia de la disciplina. A su vez, pueden consultarse los trabajos de León (2020) y Noguera-Ramírez y León-Palencia (2015), en el que se indican algunos elementos sobre el asunto en el discurso pedagógico moderno. 
Por lo tanto, debe alejarse del mundo de las envidias, tener horror de los libros prohibidos, desconfiar de sí misma, obedecer sin replicar, dejándose corregir en caso de ser necesario. Para ello se privilegia la educación moral, que forma el carácter y procura hábitos de obediencia, además de la educación intelectual y la formación del entendimiento. En prácticas como la costura, se logra cierta introyección, ya que examina sus pensamientos en silencio. A la vez, aprende a hablar de manera adecuada, cuando corresponde y lo necesario; asimismo, a ejercer dominio de sí, de sus placeres, cuando, en términos estéticos, usa lo justo, sin excesos en su manera de vestir, o al comportarse sin que sus deseos impidan el desarrollo de los de su esposo o sus hijos. Y, por supuesto, la relación con su cuerpo está mediada por la función que ha de cumplir como madre, por eso es fundamental que vigorice y fortalezca su cuerpo, que lo prepare y se prepare para la función que ha de cumplir: la de esposa y madre. Si bien habrá mujeres que decidirán ingresar a la universidad o al bachillerato —y que se encontrarían en un régimen discursivo distinto—, ello ameritará una investigación futura.

Es, pues, necesario que nuestras mujeres se convenzan de que ellas solas tienen que luchar y tomarse lo que no se les quiere dar con agrado. Esto, también, las hará más fuertes para poder aprovechar mejor las ventajas que consigan. Si los hombres, por milagro inaudito, hubieran dado hace algún tiempo a las colombianas las ventajas de que disfrutan ellos exclusivamente, quizá ellas no hubieran tenido energía suficiente para aprovecharlas. Pero ahora luchan, y cuando venzan, como tienen que vencer, serán magníficos los resultados que obtendrán sus voluntades así fortalecidas. (González, 1927, p. 426)

\section{El gobierno de sí misma: una mirada desde la educación estética}

En tercer y último lugar, como un asunto práctico, se presentan algunos elementos vinculados a la educación estética de la niña colombiana? Según se enuncia en los documentos revisados, existe en ella el apetito de crear algo bello en por lo menos tres direcciones: fuera de sí, relacionada con la creación artística; hacia sí, tendiente a la perfección y el embellecimiento de sí misma; y aquella que vincula las tendencias anteriores. La educación estética se convierte en uno de los medios de la educación moral, a propósito del cual se precisa especial precaución por cuanto puede conducir a la blandura del ánimo, que es lo opuesto al carácter.

7 Un análisis de otras prácticas vinculadas a la educación infantil femenina puede rastrearse en otras publicaciones (León, 2012, 2016) en las que se alude, entre otras, a la educación física, moral e intelectual. 
La primera de dichas direcciones, el fuera de sí, se relaciona con acostumbrar a las niñas a la contemplación de las bellezas de la naturaleza, haciéndolas comprender sus grados, armonía y la expresión de las cosas bellas, forjando que

admiren cuanto les rodea en el cielo y en la tierra; el sol, las nubes, los crepúsculos, los horizontes, las noches, etc., los campos, los bosques, los parques, las flores, etc., el agua, la lluvia, el rocío, la fuente, el arco iris, los meteoros en todo lo que tienen de bello, de grandioso y de sublime. (Ichaso, 1927, p. 126)

A su vez, se procura que perciban el sentido de la expresión, la música, el canto y la recitación, que admiren las creaciones del pincel que copia de la naturaleza todas las bellezas; por ello también se les enseña

a gustar de la poesía ya en prosa o en verso, a saberla analizar, comprender y saberla expresar, mediante recitaciones, lecturas, declamaciones, representaciones que al mismo tiempo que forman el gusto literario, educan los modales, la acción, la expresión, familiarizan con el público y aumentan el vocabulario corrigiendo modismos tan frecuentes en nuestras clases aun superiores. (p. 127)

De esta manera, la educación estética produce las impresiones que han de moldear la imaginación y los sentidos, y cuyo último objetivo es contribuir a mejorar las exigencias de la mente y el corazón. Igualmente, se debe aprovechar la tendencia de las niñas a ocuparse en ejercicios manuales, que en su educación perfeccionan las facultades y forman el gusto, a la vez que proporcionan los medios para gozar de un recreo agradable sin necesidad de nadie, proveyendo nuevos recursos que realzan el mérito personal. Se alude también al adorno de la casa, que reposa en dos asuntos: la sencillez y la armonía. La sencillez, en la que se entiende que lo útil no debe subordinarse a lo que solo sirve de adorno; por ello, un objeto bello que se ubique en el hogar debe al mismo tiempo satisfacer una necesidad particular, no solo ser atractivo por su belleza (Atkinson et ál., 1888). Y la armonía, al reconocer que deben evitarse los excesos, pues hay una cantidad justa de objetos para ubicar como parte del ornato de la casa, cada cosa tiene un lugar en la misma y por tal razón, resulta inconveniente acopiar objetos poco útiles que aumentan el desorden y representan la falta de gusto de un hogar, si no se cumplen ambos principios.

Como parte de las habilidades que debían enseñarse a las niñas se encuentra el dibujo, porque, en primer lugar, es más moral en su práctica y en sus consecuencias, que el baile o la música (Ackerman, 1824); en segundo lugar, las facultades que proporciona no se encuentran sujetas a los estragos de la edad; y tercero, se trata de una práctica más independiente que otras artes, puesto que dondequiera que se encuentre la niña 
le es fácil Ilevar consigo lápiz y papel. En particular, importa la referencia del dibujo decorativo, el cual recoge el trazo de letras en diferentes tipos; la distribución de palabras, es decir, el trazo de rótulos; la distribución de motivos y masas en espacios geométricos; la estilización de frutos, flores, hojas, árboles, etc.; ejercicios tendientes a la aplicación de normas decorativas, como la repetición o simetría; frisos y motivos de adornos para paredes, pisos, muebles, cuadernos, etc.; dibujo de libre expresión y memoria; portadas, carteles, entre otros.

El dibujo decorativo se encuentra vinculado a una práctica femenina fundamental en términos de su educación: la costura. Esta práctica se considera del todo útil para todas las niñas, nunca está de más que ellas elaboren medias por curiosidad, que hagan zurcidos, que sepan hacer un remiendo, en pocas palabras, que presenten una pieza de ropa vieja de tal modo que nadie conozca su estado a primera vista. Los zurcidos pueden usarse sobre su ropa, la de su futuro esposo e incluso en la ropa de niños menos favorecidos, pero siempre debe pasar por el ejercicio de inspección de una hábil mirada. Al tratarse de una práctica que no requiere formación intelectual, ni una especial disposición, no debe haber niña que esté eximida de saber coser. Sin embargo, sería conveniente en la práctica de la costura tener acercamiento a unos brevísimos principios de geometría plana, ya que podrían requerirse algunos de sus elementos en el momento de diseñar una prenda o adornar el hogar, de esta manera:

Se Ilama cuerpo todo lo que ocupa un lugar en el espacio, y todo cuerpo tiene lo que se llama extensión, lo cual puede considerarse de tres maneras, á saber: longitud ó largo, latitud ó ancho, profundidad ó grueso. Por ejemplo, cuando medimos 15 varas de tela para cortar un número determinado de camisas, conociendo de antemano la anchura del género, atendemos únicamente á la longitud; si para alfombrar una sala medimos lo largo y lo ancho, consideramos su superficie, es decir, longitud y latitud; si para hacer un tapete que cubra completamente una mesa ocultando sus pies, medimos lo largo, lo ancho y lo alto de aquel mueble, puede decirse que atendemos á su volumen. (Atkinson et ál., 1888, pp. 153-154)

La segunda dirección del gobierno de sí, tendiente a la perfección y embellecimiento de sí misma, tiene que ver con las galas y afeites de su cuerpo, los cuales no deben comprender la misión de su vida; sus encantos deben proceder de la limpieza, la proporción y comodidad de la ropa, que puede ser agradable y cómoda, mas no reemplaza a la verdadera belleza que representa ser una niña virtuosa. El vestido debe adaptarse a los movimientos del cuerpo, a la vez que cubrirlo y defenderlo de las inclemencias del clima y, como asunto secundario, buscar adornar y embellecer a la persona, pero ello depende en gran medida de la salud, puesto que los excesos y la sofisticación de ciertas modas resultan 
contraproducentes para esta. Es un riesgo permanente para la mujer caer en excesos a la hora de su preocupación por vestir a la moda, lo que implica costos innecesarios, apenas se requiere que los vestidos "estén sin rotulas ni descosidos de ninguna especie, se conserven limpios, se lleven con elegancia, con peinado sencillo y accesorios adecuados" (Atkinson et ál., 1888, p. 130).

El tercer aspecto vincula el sentido estético externo, es decir, el relacionado con la contemplación de la belleza y la creación artística, y, el que debe ejercerse sobre sí, dirigido al embellecimiento. El equilibrio entre estos dos aspectos debe cuidarse al evitar caer en excesos y fruslerías perjudiciales cuando la niña ejerza el lugar que como madre y esposa ha de ocupar.

\section{Consideraciones finales}

Gobernar la casa, gobernar la familia y gobernarse a sí misma operaron como imperativos de la educación infantil femenina en Colombia durante la primera mitad del siglo xx. Tales imperativos transformaron la educación de la niña, otrora centrada en la transmisión que ejerce la madre hacia su hija a través del ejemplo, y se concretaron entre finales del siglo xIx y la primera mitad del siglo xx en la escolarización femenina, en la cual se asigna a la niña la responsabilidad de dirigir el futuro de la población. Escolarizar a la niña supuso la proliferación de numerosas instituciones escolares dedicadas a su educación ${ }^{8}$; la publicación de manuales de urbanidad, pedagógicos o de puericultura, artículos en revistas pedagógicas y de circulación nacional, entre otros documentos destinados a la lectura femenina y, por último, el fortalecimiento del discurso médico dirigido a la niña a través de un conjunto de recomendaciones, prohibiciones y culpabilizaciones a aquella que no realizara adecuadamente dicho gobierno.

Gobernar significa que la niña conduzca la conducta de quienes habitan el hogar familiar, sean estos los sirvientes, su esposo e hijos o ella misma, a través de su administración, es decir, al definir su materialidad, las relaciones entre los individuos y las formas como ellas se producen, determinando las prácticas de alimentación, higiene y vestido, destinando los tiempos para cada actividad, haciendo suya la práctica de cuidado, invirtiendo los recursos familiares, entre otros. En síntesis, asumiendo la responsabilidad de la vida de quienes habitan el microcosmos familiar. Por tal motivo, fue preciso educar a la niña y garantizar que, por la vía del gobierno que esta ejercía sobre sí misma, pudiese gobernar a otros.

8 Asunto analizado ampliamente por otros autores (Sánchez, 1999; Vahos, 2002) y que no fue materia del presente trabajo. 
No obstante, gobernar a otros fue posible gracias a un esquema de orden conceptual, político y práctico. En términos conceptuales a partir del desdibujamiento de la mujer descrita como el bello sexo y la ascensión de la mujer moderna; en términos políticos, en la asignación de la responsabilidad de conducir a otros y por lo tanto la necesidad de dominar la ciencia del hogar y finalmente, en términos prácticos, a partir de la puesta en escena

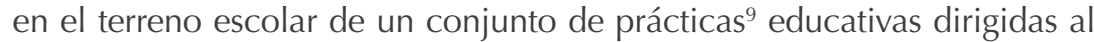
gobierno que la infancia femenina debía ejercer sobre sí, en especial y como un ejemplo de ello, a propósito de la educación estética.

Estos hallazgos dejan al descubierto una potente estrategia de gobierno de la población de la cual la niña fue pieza clave, lo que excedería una lectura que apenas denuncia las desigualdades entre niño y niña o entre hombre y mujer. En otras palabras, que el lugar privilegiado para la vida femenina fuese el microcosmos familiar, empoderó su accionar social, familiar e individual. Por este motivo, este análisis se distancia de ciertas lecturas que interpretan de manera subordinada y empobrecida lo femenino en el universo del hogar, por el contrario, a través de esta lectura se reconoce que esta fue una posibilidad de empoderamiento femenino, allí, la niña - como futura madre y esposa - tendría la tarea nada despreciable de definir la manera en que otros (esposo e hijos) practican la vida, expresada en asuntos como la alimentación, el descanso o la interacción con el espacio, entre otros aspectos.

Por último, insistir en la radicalidad pedagógica de estas líneas pasa por describir la configuración a través de la educación de la forma infantil femenina, enmarcada en la circulación de técnicas, la producción discursiva y la emergencia de escenarios educativos en los que dicha forma tuvo lugar. El esquema sugerido aquí, con sus componentes conceptual, político y práctico, puede entenderse como parte del saber pedagógico que se constituyó en referente para la educación infantil femenina a finales del siglo xIx e inicios del xx en nuestro país. Sin embargo, dicho esquema también opera como una marca cuyo registro en multiplicidad de documentos, de los que apenas se toma una exigua selección en el presente trabajo, nos habla de la complejidad de las formas de subjetivación de lo femenino, asunto que hoy en día parece quedar en el olvido. No en vano, la tarea de la pedagogía justamente ha estado relacionada con la educación y formación de aquello que hace varios siglos hemos consentido en Ilamar "lo humano" y que en las últimas décadas ha entrado en una suerte de crisis. Si, como lo indica Biesta (2013), la cuestión sobre lo que significa

9 Es importante anotar que la configuración de estas prácticas obedece a la conjunción y articulación entre técnicas (entendidas como aquellas operaciones configuradas a través del tiempo) y fines (que sirven como orientadores de dichas técnicas). Un análisis de esa articulación puede encontrarse en Marín-Díaz y Parra-León (2019). 
ser humano es sobre todo educativa (en la medida en que implica una intervención en la vida de alguien, motivada por una idea de aquello en que se tornará esa vida, en cierto modo, más completa, armoniosa o perfecta —y quizá más humana-), este escrito abordó la forma en que en un periodo histórico específico (finales del siglo xix e inicios del xx) a través de prácticas educativas (dirigidas a la educación infantil femenina) se propuso un modo particular de practicar la vida.

\section{Referencias}

Acevedo de Gómez, M. (1848). Tratado sobre economía doméstica para el uso de las madres de familia e de las amas de casa. Imprenta de José A. Cualla.

Ackermann, R. (1824). Cartas sobre la educación del bello sexo por una señora americana. S. E.

Acosta de Samper, S. (1895). La mujer en la sociedad moderna. Casa Editorial Garnier Hermanos.

Atkinson, F.; García, J; Sellén, F. y Molina, E. (1888). Economía e higiene doméstica de Appleton. Arreglada para el uso de las escuelas y de la familia en general. D. Appleton and Company.

Bermúdez, S. (1993). El bello sexo: La mujer y la familia durante el Olimpo Radical. Uniandes y ECOE.

Biesta, G. (2013). Para além da aprendizagem: Educação democrática para um futuro humano. Autêntica Editora.

Butler, J. (2002). Cuerpos que importan: Sobre los límites materiales y discursivos del "sexo". Paidós.

Cambell, J. (1926, 13 de marzo) Que gobiernen las mujeres. El Gráfico: Semanario llustrado, (15), 774.

Castellanos, V. (1933). Autodominio por la educación. Educación. Órgano de la Facultad de Educación de la Universidad Nacional, 1(2), 106-109.

Dupanloup, F. (1995). La mujer estudiosa: Algunos consejos a las mujeres cristianas que viven en el mundo sobre el trabajo intelectual que les conviene. Servicio de Publicaciones de la Universidad de Cádiz. Publicado originalmente en 1888.

Fenelón, F. de S. (1934). La educación de las niñas: Pedagogía (traducción de María Luisa Navarro de Luzuriaga). Talleres Espasa-Calpe.

González, J. (1927, 10 de diciembre). La mujer en la universidad. El Gráfico: Semanario llustrado, (16), 861.

Ichaso, R. (1927). La enseñanza nacional femenina. Imp. Intendencia de Guerra. 
León, A. C. (2012). Constitución del sujeto infantil femenino en Colombia: finales del siglo XIx, comienzos del xx: Entre el gobierno de sí y el gobierno de los otros. [Tesis inédita, Universidad Pedagógica Nacional].

León, A. C. (2012). Cartografía de los saberes y prácticas de la educación infantil femenina en Colombia: Finales del siglo XIX, comienzos del siglo xx. Pedagogía y Saberes, 37, 9-23.

León, A. C. (2016). ¿Qué significó educar la niña colombiana? Finales del siglo xIx y comienzos del xx. En A. Vechia, y A. Gomes (Orgs.), A criança e a escolarização: Igualdade e desigualdade no espaço latino-americano nos séculos XIx e Xx (pp. 226-248). Universidade Tuiuti do Paraná.

León, A. C. (2020). Los hijos no quieren ser como sus padres: Infancia, pedagogía y antropotécnicas. En Aguilar, R. y Giraldo, M. (Eds.), (2020). Lecturas críticas sobre infancia: Tensiones entre la modernidad y la contemporaneidad (pp. 79-106). Aula de Humanidades y Universidad de Antioquia.

Marín, D. y Noguera, C. (2013). El arte de gobernar moderno: O de la constitución de una ciencia de la educación. Educação, 36(2), 156-167.

Marín-Díaz, D. y León-Palencia, A. C. (2018). Infancia: Balance de un campo discursivo. Universidad Pedagógica Nacional.

Marín-Díaz, D. y Parra-León, G. (2019). La noción de práctica: Posibilidades para pensar en educación. En M. Lopes y J. Morgenstern (eds.), Inclusão e subjetivação: Ferramentas teórico-metodológicas (pp. 41-58). Appris Editora.

Noguera-Ramírez, C. y León-Palencia, A. C. (2015). Foucault revisitado: Uma releitura da disciplina através do conceito de antropotécnica. En A. Filordi de Carvalho, y S. Gallo (orgs.), Repensar a educação: 40 anos após vigiar e punir (pp. 209-239). Editora Livraria da Física.

Restrepo Mejía, M. (1914). Pedagogía doméstica. Lit. F. Madriguera.

Ruíz Amado, R. (1912). La educación femenina. Librería Religiosa.

Sánchez, M. (1999). Análisis de las diversas representaciones de la Mujer en Bogotá 1880-1920: Informe final. Fundación para la Promoción de la Investigación y la Tecnología-Banco de la República.

Scott, J. (1990). Género: una categoría útil para el análisis histórico. En J. Amelang y M. Nash (eds.), Historia y género: Las mujeres en la Europa moderna y contemporánea. Ediciones Alfons El Magnanim.

Vahos, L. (2002). Mujer y educación en la Nueva Granada. Comunicación Creativa. 